\title{
Impact of Social Support Resources on Post- Purchase Dissonance: Evidence from Jordan
}

\author{
Dr. Abdullah Matar Al-Adamat \\ Department of Business Administration \\ Faculty of Economics and Administrative Sciences \\ Al al-Bayt University \\ Mafraq, 25113, Jordan \\ Dr. Omar Atallah Al-Adamat \\ Ministry of Education \\ Mafraq, 25454, Jordan
}

\begin{abstract}
This article aims to address the paucity of research into the impact of social support resources - family, friends and significant others - on post-purchase emotional and cognitive dissonance amongst young consumers. For the purposes of the study, a quantitative survey was undertaken of 564 randomly selected undergraduate purchasers of smart phones at six Jordanian universities. Data analysis revealed that social support had a statistically significant impact on emotional dissonance for males in the group. It had no bearing on emotional dissonance amongst females in the survey. However, the findings indicate an influence upon levels of cognitive dissonance experienced by both males and females. Consumer cognitive dissonance appears to increase in direct proportion to levels of familial influence surrounding the purchase. This study is one of only a limited number offering empirical evidence of the effects of social support systems on post-purchase dissonance.
\end{abstract}

Keywords: Cognitive Dissonance, Emotional Dissonance, Post-Purchase Dissonance, Social Support Resources

\section{1- Introduction}

The need to maintain harmony within cognitive and behavioural systems can be adjudged a part of the human condition. Individuals crave coherence amongst their opinions and ideas, and any discrepancy causes individuals to experience unease. Cognitive dissonance refers to the effects emanating from the attempt to maintain two conflicting opinions. According to Nail and Boniecki (2011), dissonance theory is a well-established model within the field of psychology. For Festinger (1957),the theory infers that individuals encounter internal discord when compelled to choose. Dissonance reduction is pursued by diminishing the alleged desirability of rejected choices and increasing the professed value of chosen alternatives. If choice confirmation cannot be bolstered with supporting information, then attitudes themselves can be modified to correspond to the choice. The relationship between dissonance and consumer behavior has been the subject of valuable research. As Hasan and Nasreen (2012) point out, the concept has unsurprisingly attracted the attentions of the world's collective marketing imagination. It is Festinger's model in particular, explain Telciet al. (2011), that has been chosen as a blueprint by marketing theorists in their common quest for the truth behind consumer behaviour. Oliver (1997) has investigated the role of dissonance throughout the entire decision-making process in purchasing. Classic models of consumer behavior divide the process for the purchaser into stages - pre-purchase, exchange and post-purchase (Sheth, 1969; Engel et al.,1978). Any cognitive dissonance occurring after a purchase is referred to as postpurchase dissonance. Typically, this phenomenon arises in the presence of any remaining cognitive discrepancy after the formulation of the purchase decision. Post-purchase dissonance is in fact quite normal. Bose and Sarker (2012) assert that the simple reason for this is that almost any purchase decision necessarily involves an element of compromise. This is what Cooper (2007) insinuates when he describes the disjoint between anticipation and realization that inevitably leaves the customer in a disagreeably inharmonious condition, feeling a mixture of confusion, frustration and invariably disappointment.

The inherent difficulty when attempting to quantify post-purchase dissonance is as a direct result of the fact that marketing concepts are challenging to gauge in situ. 
There have, however, been several attempts at laboratory-based research into consumer behavior, including work by Holloway (1967), Hunt (1970), Oshikawa (1972), Korgaonkar and Moschis (1982) and Milliman and Decker (1990). Yet, Telciet al. (2011) maintain that such research has intrinsic methodological flaws. A scale system expounded by Sweeney et al. (2000) may be the solution and promises to facilitate research into purchase related dissonance. In their work, Sweeney et al. (2000) separated dissonance into its cognitive and emotional elements. With the former, the purchaser considers in hindsight the relative prudence of a purchase they have made. On the other hand, with emotional dissonance the emphasis is on the mental discomfort arising post-purchase (Clark \& Das, 2009).

According to Schiffman and Kanuk (2009), consumers seek affirmation of the wisdom of their choices from advertisements and fellow consumers. Dissonance will prevail, however, when choice is extensive, but information is not. As Li and Lai (2014) have suggested, pursuing social support in purchasing decisions is deemed a viable solution. Social support refers to assistance received during moments of crisis and Zimet et al. (1988) consider the three main bases of this support to be the family, friendship groups and significant partnerships. Nevertheless, Thoits (1986) and Horowitz et al. (2001) have all suggested a possible counterproductive dimension to this help. If the support in question were deemed time-wasting, irrelevant or in any other aspect contrary to the assistance the recipient desired, their emotional discomfort far from declining might actually increase. This interplay between social support and levels of dissonance has been studied by McKimmieet al. (2003), who looked at the subject from a social identity perspective.

Despite their compatible prognostic capacities, theories of social influence and cognitive dissonance have never, in Tanford and Montgmery's (2015) view, been seriously united within any one single research programme. Furthermore, if Telciet al.(2011) are to be believed, recent years have witnessed a notable waning of interest in cognitive theory. Against this background, this paper aims to present an empirical investigation into the affect upon post-purchase dissonance levels of three main sources of social support. Specifically, these are familial, friendship-based and significant other support. This paper explicitly focuses on levels of post-purchase emotional and cognitive dissonance amongst young males and females and the relationship between this and the extent of their social support resources. The intention here is to provide for the marketing industry a means for recognizing the impact of social support on post-purchase dissonance amongst young people.

\section{2- Literature Review}

\subsection{Post Purchase Dissonance}

As Sharma (2014) succinctly elucidates, when incongruity exists between ideas and actions, something must change so that the dissonance is dispelled. Festinger (1957), Harmon-Jones et al. (2011) and Brown-Wright et al. (2013) have all defined dissonance as a mentally distressing situation from which individuals are compelled to extricate themselves by modifying belief systems and behaviour patterns. Hasan and Nasreen (2012) see dissonance as the factor prompting individuals to bestow concord and consistency upon discordant elements to thereby eliminate psychological distress. That dissonance has both emotional and psychological dimensions has been emphasized by Sweeney et al. (2000). Festinger (1957) refers to cognitive dissonance as that unhappy state of being when persons possess two thoughts, or cognitions, incapable of co-existence. Perplexity and stress must consequently manifest themselves, not least because individuals regard both cognitions as valid. Bids to reduce tension are attempted in three ways, as described by Telciet al. (2011). The individual may try to remove discordant thoughts. On the other hand, they might seek to add innovative harmonious thoughts. Alternatively, the person could simply reduce the incompatible thoughts.

Festinger's groundbreaking work on dissonance inspired countless empirical investigations, particularly by researchers within the disciplines of sociology and psychology (Mao \& Oppewal, 2010). Some, like Aronson (1968) proclaimed Festinger's theory to be one of the most significant in the entire field of social psychology. It has been shown by Rodrigues et al. (2018) that intra-individual or internal processes like dissonance reduction and the management of corroborative facts are culturally relative. Within any given social context, the value ascribed to information and the cognitive processes which do the interpreting are constrained by social variables. Work by Hoshino-Browne et al. (2005) demonstrates that although the experience of dissonance if familiar to individuals in both Western and Eastern cultures, the individuals' different cultural memberships define the contexts for the manifestation and dissipation of this dissonance. 
Following its inception in psychology, cognitive dissonance rapidly found favour with marketing theorists. Telci et al. (2011) notes how its main relevance was to the study of consumer behavior, particularly in the postpurchase context. Montgomery and Barnes (1993), for example, have produced work which argues that understanding cognitive dissonance is vital due to its associations with opinion fluctuations, stress and dissatisfaction amongst customers. Hettiarachchi et al. (2017) explain how concepts of consumer behavior can aid the comprehension of decision-making, defined as a multiple-layered process of which the act of purchasing constitutes the key aspect. Kotler and Armstrong (2010) extend this by explaining that any post-purchase actions are driven by customer satisfaction which is turn is steered by what Hettiarachchi et al.(2017) describe as the deficit between what the customer anticipates from the product or service and what they perceive they have received.

A number of models are available to facilitate the analysis the relationship between consumer behaviour patterns and cognitive dissonance (Van Overwalle \& Jordens, 2002), including the consonance model utilized by Shultz and Lepper (1996). The latter is a constraint connectionist model in which a subject's representation of the dissonance-inducing experimental situation can be reflected. Alternatively, there is the action-based model which predicts that an action-oriented disposition facilitates cognitive dissonance reduction. Harmon-Jones and HarmonJones (2002) devised two investigations to test the hypothesis, the results of which indeed appear to support the action-based model. The scale developed by Sweeney et al. (2000), as mentioned above, has been utilized by Soutar and Sweeney (2003) and O'Neill and Palmer (2004) to promote additional exploration into the existence of differing levels and types of dissonance within segments. In the opinion of O'Neill and Palmer (2004), consumers disremember their experiences in the period following the consumption of goods and service and simply proceed to establish pristine expectations in fresh contexts as they arise.

It could be contended that the physiological difference between men and women might result in disparate dissonance levels. Soutar and Sweeney (2003) propose that the perceived male tendency towards less focused and more aggressive responses could be seen as linked to greater experiences of dissonance. Conversely, according to Dittmar and Drury (2000), females take a more logical approach which can more readily rationalize dissonance. Age is clearly a factor too. In the case of technological goods, younger consumers engage in more sophisticated purchase behaviours. Graff et al.(2012) note the tendency of this group to research products prior to purchase, a habit which, according to Thompson et al.(1993), creates higher expectations. In contrast, older consumers approach such purchases more steadily and place greater trust in sales personnel. Soutar and Sweeney (2003) inevitably conclude that younger consumers will experience higher levels of dissonance than the more mature counterparts.

Despite its countless critics, dissonance theory remains, according to Harmon-Jones and Harmon-Jones (2007), a useful critical and investigative tool. However, Cohen and Goldberg (1970) remind us that dissonance theory fails to address the fact that through their reasoning for and vindications of their errors, individuals increase the probability of their persistently repeating their own misjudgments.

\subsection{Social Support Resources}

Crano's (2000) contention that social influence and support are a major theme in social psychology is supported by the plethora of definitions it invokes. Hall and Wellman (1985) define social supports as the assistance that is given by others and social networks as the structures through which that assistance is negotiated and facilitated. Li and Lai (2014) take a similar approach, adding the dimension of a trusted space for information exchange wherein the opinions of those within the social network can provide both support and advice. As O'Reilly (1988) summarizes, the social network is the structure the social support is the function. Notionally at least, social support simply describes an individual's experience of sustenance and affirmation by virtue of their membership of a social group (Cobb, 1976; Ali, 2011), but in practice it is much more than this suggests. Hettiarachchi et al. (2017) refer to the implications social support has for consumer behavior. The importance of friendship and familial networks as wielders of pressure is discussed by Taylor and Todd (1995), who add that social networks can also act as determiners of product preference. Regarding cross-cultural differences, Alekam et al. (2013) summon attention to the fact that social network pressures are likely to possess greater potency within societies which manifest a robust collectivist ethos since community bonds within such cultures tend to be more keenly experienced and expressed. Compliance is a recognized by-product of social influence, explains Kelman (1958), whereby individuals publicly conform with mainstream views but internally retain their original beliefs. 
Tanford and Montgomery (2015) concur with this opinion, adding that the arrival of the internet and the rise of social media have both exacerbated the role of social influence in purchase decisions. It was discovered by McKimmieet al.(2003) that persons lacking support from leading social cliques had a greater tendency to seek dissonance reduction by altering their beliefs and lessening their group affiliations. Nevertheless, social support from a trusted partner remains a swift and sound route to a satisfactory purchasing experience, according to Kamis and Frank (2012). Conversely, Hasan and Nasreen's (2012) research suggests greater participation by family and friendship support groups during the decision-making stage has a higher probability of rendering the consumer more prone to dissonance.

\section{3- Methodology}

One key aim of this study is to clarify the link between social support resources and post- purchase dissonance. Owing to the high descriptive and explanatory content of the research undertaken to explore this relationship, analysis has required a deductive approach and quantitative research methods were used.

A sample of $\mathrm{N}=564$ undergraduate students (247 Female and 317 Male) participated in this study. The sample was taken from six universities, randomly selected from amongst the ten public universities in Jordan, and the research was conducted in March 2018.

A self-administered questionnaire was employed as the primary means of data collection. There were two measurable elements embodied within the questionnaire - social support and post-purchase dissonance - and each was measured on a five-point Likert scale, where in one point signifies strongly disagree and five points denotes strongly agree. Additional data regarding product price, purchase time and demographic information were also garnered.

Measurements of levels of social support were framed around the twelve-item Multidimensional Scale of Perceived Social Support (Zimetet al., 1988). This scale is in turn structured around the concept of friendshipbased, familial and SO (special other) sources as the providers of social support. The data in the current study endorses the overall reliability of the scale, which was found to be $85.0 \%$ for overall reliability, $81.8 \%$ for family support (four items), $74.3 \%$ for friend support (four items), and $83.7 \%$ for special other (SO) support (four items). Quantification of post-purchase dissonance was conducted according to the twenty-two-item scale introduced by Sweeney et al. (2000). This particular scale was specifically designed to measure cognitive dissonance occurring in the period directly following product or service acquisition. Sweeney et al. (2000) selected for inclusion on their scale the three so-called dimensions of dissonance. Thus, one emotional dimension and two cognitive dimensions, including the wisdom of purchase and concern over the deal, can be seen to have been incorporated for measurement. Data analysis from the study confirmed the dependability of the scale. Specifically, the scale's reliability was determined to be $95.7 \%$ overall, $97.7 \%$ for the emotional response (fifteen items), $84.5 \%$ for wisdom of purchase dimension of cognitive dissonance (four items), 91.6\% for the concern over deal dimension of cognitive dissonance (three items), whilst the reliability for the overall cognitive response (seven items) was $87.8 \%$.

Primary data were collected in accordance with the survey research approach via a questionnaire administered to a sample group. The questionnaire method permits the rapid collection, coding and consideration of large quantities of data. Quantitative data analysis was performed with the assistance of Statistical Package for Social Science (SPSS) version 19.0. Several relevant statistical testing techniques were contemplated and ultimately Cronbach's coefficient alpha method, descriptive statistics, the independent samples t-test, the Pearson correlation analysis, and multiple regression analysis were selected as the most fitting and pertinent for addressing the current research goals.

\section{4- Data Analysis and Results}

This section outlines the results from the investigation's statistical tests. To begin with, there are the descriptive measurements of Social Support Sources, Emotional Dissonance, and Cognitive Dissonance (see Table 1) for which an independent-samples $t$-test was conducted to enable a comparison of male and female scores. As can be seen from Table 1, females in the study sample registered higher levels of perceived social support than male respondents, as observed in the score differential for Total Social Support which was males $(M=3.82 \pm 0.44)$ and females $(M=4.1 \pm 0.55) ; t(562)=-4.5, p \leq 0.05$. These results confirm the presence of gender variance in perceived social support levels. 
The analysis reveals a meaningful correlation between emotional and cognitive dissonance $(r=0.407 ; p<0.001)$ pertaining to post-purchase dissonance. On the other hand, subjects reported moderate levels of emotional dissonance with no meaningful disparity between males $(M=2.33 \pm 1.25)$ and females $(M=2.26 \pm 1.05)$ and above-moderate levels of cognitive dissonance with no significant difference between males $(M=3.36 \pm 1.03)$ and females $(M=3.44 \pm 1.01)$ (see Table 1).

Table (1): Descriptive Statistics and t-Test Results

\begin{tabular}{|c|c|c|c|c|c|}
\hline Variables & Sex & Mean & $\mathrm{SD}$ & $t$ test & Sig. \\
\hline \multirow{2}{*}{ Family Support } & Male & 3.76 & 1.08 & \multirow{2}{*}{-5.652} & \multirow{2}{*}{0.000} \\
\hline & Female & 4.23 & 0.80 & & \\
\hline \multirow{2}{*}{ Friend Support } & Male & 3.70 & 0.95 & \multirow{2}{*}{-0.422} & \multirow{2}{*}{0.673} \\
\hline & Female & 3.73 & 0.87 & & \\
\hline \multirow{2}{*}{ Other Support } & Male & 4.00 & 1.01 & \multirow{2}{*}{-4.201} & \multirow{2}{*}{0.000} \\
\hline & Female & 4.33 & 0.86 & & \\
\hline \multirow{2}{*}{ Total Social Support } & Male & 3.82 & 0.84 & \multirow{2}{*}{-4.498} & \multirow{2}{*}{0.000} \\
\hline & Female & 4.10 & 0.55 & & \\
\hline \multirow{2}{*}{ Emotional Dissonance } & Male & 2.33 & 1.25 & \multirow{2}{*}{0.768} & \multirow{2}{*}{0.443} \\
\hline & Female & 2.26 & 1.05 & & \\
\hline \multirow{2}{*}{ Cognitive Dissonance } & Male & 3.36 & 1.03 & \multirow{2}{*}{1.0188} & \multirow{2}{*}{0.309} \\
\hline & Female & 3.44 & 1.01 & & \\
\hline
\end{tabular}

N: Males $=317$ and Females $=247$

In order to address the main research question, it was necessary to conduct a multiple regression analysis in which social support sources were the independent variables and dissonance was the dependent variable. This was applied to both male and females in the study.

Table (2): Multiple Regression Analysis of the Impact of Social Support Sources on Emotional Dissonance among Males

\begin{tabular}{|l|l|l|l|l|l|l|l|}
\hline Predictors & Beta & $\mathrm{t}$ & Sig. & $\mathrm{R}$ & $\mathrm{R}^{2}$ & $\mathrm{~F}$ & Sig. \\
\hline Family Support & .149 & 1.899 & 0.059 & & & & \\
\cline { 1 - 5 } Friend Support & .112 & 1.742 & 0.083 & 0.261 & 0.068 & 7.471 & 0.000 \\
\hline Other Support & -.374 & -4.567 & 0.000 & & & & \\
\hline
\end{tabular}

Predictors: Family Support, Friend Support and Other Support

Dependent Variable: Emotional Dissonance

The results set out in Table 2 indicate that predictors of social support sources only account for the variance in emotional dissonance levels recorded among male respondents as expressed by $R$ square value $\left(R^{2}=0.068\right)$. Since the $F$ test value is equal to (7.471) and its statistical significance is ( $p$ value $\leq 0.00$ ), there exists a statistically significant effect for the sources of Social Support on emotional dissonance in male respondents. In contract, special other (SO) support is the only area where social support has a meaningfully negative influence on emotional dissonance amongst males in the sample group as can be seen here: $(\beta=-0.37, t=-4.57, p$ value $\leq$ 0.05). In essence, the findings in this respect signify that higher levels of SO (special other) support will produce decreased levels of emotional dissonance in males. Neither familial nor friendship-based support made any statistically significant impact on levels of emotional dissonance among male respondents in the study ( $p$ value > $0.05)$.

Table (3): Multiple Regression Analysis of the Impact of Social Support Sources on Emotional Dissonance among Females

\begin{tabular}{|l|l|l|l|l|l|l|l|}
\hline Predictors & Beta & $\mathrm{t}$ & Sig. & $\mathrm{R}$ & $\mathrm{R}^{2}$ & $\mathrm{~F}$ & Sig. \\
\hline Family Support & .064 & .977 & 0.330 & & & & \\
\cline { 1 - 5 } Friend Support & .055 & .842 & 0.401 & 0.142 & 0.020 & \multirow{2}{*}{1.626} & 0.184 \\
\hline Other Support & .091 & 1.367 & 0.173 & & & & \\
\hline
\end{tabular}

Predictors: Family Support, Friend Support and Other Support

Dependent Variable: Emotional Dissonance 
Table 3 shows the value of ( $F$ test) to be equal to $(1,63)$, and the statistical significance to be $(0.184)$. The implication of this result is that there does not exist for female respondents in the sample a statistically significant effect on emotional dissonance of any of the three dimensions of social support, that is family support, friend support or special other (SO) support. Table 4 demonstrates the statistical significance of the three social support dimensions on cognitive dissonance amongst males in the study as findings reveal the $F$ test value is equal to (8.47) and its statistical significance is $(p$ value $\leq 0.00)$. Friend support amongst males has no meaningful impact on their cognitive dissonance. An identical result was noted in the case of SO (special other) support. However, an analysis of the data related to familial support amongst male respondents produced unexpected findings. This category of influence was shown to have a positive impact on cognitive dissonance amongst the males in the sample $(\beta=0.16, t=2.1, p$ value $\leq 0.05)$. These findings confirm that elevated levels of familial support produce enhanced cognitive dissonance in males.

Table (4): Multiple Regression Analysis of the Impact of Social Support Sources on Cognitive Dissonance among Males

\begin{tabular}{|l|l|l|l|l|l|l|l|}
\hline Predictors & Beta & $\mathrm{t}$ & Sig. & $\mathrm{R}$ & $\mathrm{R}^{2}$ & $\mathrm{~F}$ & Sig. \\
\hline Family Support & .163 & 2.101 & 0.036 & & & & \\
\hline Friend Support & .051 & .809 & 0.419 & 0.274 & .075 & 8.470 & 0.000 \\
\hline Other Support & .101 & 1.247 & 0.213 & & & & \\
\hline
\end{tabular}

Predictors: Family Support, Friend Support and Other Support

Dependent Variable: Cognitive Dissonance

As a final point, it is useful to note that the study demonstrated the importance of social support for cognitive dissonance reduction amongst females as evidenced in the $F$ test value which is equal to (5.00) with the statistical significance ( $p$ value $\leq 0.00$ ) (see Table 5). In addition, SO (special other) support as a meaningful positive effect on cognitive dissonance for females $(\beta=-0.15, t=-2.27, p$ value $\leq 0.05)$. In summary, it appears to be the case that greater family support and/or SO (special other) support result in raised levels of female cognitive dissonance, whereas there is no statistical evidence pointing to a similar link between friend support and female cognitive dissonance.

Table (5): Multiple Regression Analysis of the Impact of Social Support Sources on Cognitive Dissonance among Females

\begin{tabular}{|l|l|l|l|l|l|l|l|}
\hline Predictors & Beta & $\mathrm{t}$ & Sig. & $\mathrm{R}$ & $\mathrm{R}^{2}$ & $\mathrm{~F}$ & Sig. \\
\hline Family Support & .145 & 2.274 & 0.024 & & & & \\
Friend Support & -.042 & -0.664 & 0.507 & 0.241 & 0.058 & 5.004 & 0.002 \\
\hline Other Support & .164 & 2.531 & 0.012 & & & & \\
\hline
\end{tabular}

Predictors: Family Support, Friend Support and Other Support

Dependent Variable: Cognitive Dissonance

\section{5-Discussion}

One general conclusion that can be drawn from this study is that there exists a high level of perceived social support amongst undergraduate students at public universities in Jordan. Such a finding is expected; as Jordanian culture, in common with that of other Arab societies, is typified by close social relationships and attachments. The observation that females reported higher perceived levels of familial support than males is consistent with observations made by Soliman (1993). Furthermore, data from the study discussed within this paper indicate a possible disparity between males and female perceptions of social support by a special other (SO), with females again recording higher levels. When these findings are contextualized within nurturing practices for males and females in Eastern Arab culture, an explanation for the differences appears. That is, whilst females are expected to develop highly intimate interpersonal and interdependent relationships within the family, males are urged to acquire characteristics such as autonomy, resourcefulness and dependability. However, the absence of genderbased differences in perceived levels of support from friendship sources reveals the benefits of this support for both males and females. The research disclosed low levels of post-purchase emotional dissonance amongst the Jordanian undergraduates, notably a range of 2.26 to 2.33 on a scale of 5 . 
Moderate levels of cognitive dissonance were recorded, in the range of 3.36 to 3.44 on the same scale, which may be a product of the tie and money perceived as invested in the purchase of the product in question along with the infrequent nature of such an acquisition. Previous work in this area, such as that by Sweeney et al.(2000), Mao and Oppewal (2010) and Gan and Ding (2014), hypothesize a meaningful link between cognitive and emotional dissonance. The suggestion is that the emotional element embodied in dissonance has a positive relationship with the cognitive element, as propounded by Sweeney et al.(2000). Hence, Mao and Oppewal's (2010) contention that any psychological disquiet over purchase should have a positive link with the level of unease experienced over the so-called wisdom of purchase.

The findings reproduced in this paper indicate an absence of gender-based differences in emotional dissonance. Likewise, there exists no disparity in cognitive dissonance that can be ascribed to gender variables. Both conclusions can be ascribed to the parallels between male and female experiences of cognitive dissonance and their analogous belief systems. These factors are themselves a consequence of the comparable life experiences of both genders and the not dissimilar information to which both males and females are exposed. The comparable educational paths and milieu of males and females is no doubt also a determining factor. Such findings lend support to other researchers' results, such as those of specifically Reiger (2000), Armstrong et al.(2017), Mao and Oppewal (2010) and Graffet al.(2012), whose work also demonstrates the insignificance of gender to postpurchase dissonance. In contrast, the findings expressed here deviate appreciably from those of Jamwal and Pandy (2016) who concluded that the gender variable did have an effect on post-purchase dissonance. However, the discrepancy between the current findings and those of Jamwal and Pandy (2016) may emanate from cultural and demographic differences between the respective sample groups involved.

On the question of the influence of the emotional dissonance dimension known as SO (special other) support, this was only recorded as having a significant impact with males in the study group. No social support group demonstrated a potential for influence on emotional dissonance amongst the female respondents. One consideration here must be the nature of the product in question. The study focused on post-purchase dissonance experience in connection with the acquisition of a technological product in the shape of a smart phone. Arguably males are more invested in this type of product on many levels. Graff et al.(2012) have observed that expectations surrounding technological appliances are pitched higher amongst males than females. Such elevated levels of anticipation might be seen to cause males to depend more on SO support to mitigate any emotional dissonance arising in the post-purchase period.

The most exciting conclusion to be drawn from this study is the evident affiliation between social support and post-purchase cognitive dissonance as reported by both genders in the study group. This relationship manifested in the reporting of raised levels of perceived post-purchase cognitive dissonance amongst males and females who were deemed to possess higher levels of social support. Furthermore, it has been shown that the higher the degree of perceived familial and SO support, the greater the post-purchase cognitive dissonance faced by the individual concerned. This may have a strong association with whether the respondent made the purchase choice independently or under the unwelcome aegis of another source such as a family member. These findings are consistent with those of Hasan and Nasreen (2012) who isolated a strong correlation between familial influence and dissonance levels. The influence of culture as a determiner of the contexts in which dissonance is induced or reduced has been noted, not least by Rodrigues et al.(2018). Hoshino-Browne et al.(2005) concur and their research suggests that the influence of friendship upon cognitive dissonance is culturally driven. The findings from the Jordanian study reported in this paper in fact showed no influence was exerted on cognitive dissonance by perceived social support from friends. This may in turn be attributable to cultural context.

\section{6- Conclusions and Recommendations}

This paper is an attempt to understand the influence of social support on post-purchase dissonance. It is hoped the findings might be of assistance to market specialists both in their search to understand the relationship between social support resources and post-consumer dissonance and in their endeavours to improve marketing initiatives. It is the intention of the researchers to add the caveat that lack of extant empirical investigation into this subject and the relative novelty of this field of research demands the adoption of a degree of caution when interpreting any findings. The subjects of the study were Jordanian university undergraduates, a group typically associated with constrained pecuniary means and thus perhaps not accustomed to the high-level expenditure associated with the product purchase involved in this study. This might have implications for the detection of any post-purchase dissonance within the study sample. 
Were the survey to have been conducted in another country or amongst a different demographic group, it might well have yielded entirely different results. Finally, this investigation centred exclusively on the post-purchase context, but there is an obvious justification for bringing all stages in the purchase process within the ambits of comparable studies.

\section{References}

Alekam, J. M. E., Al Anazi, A. A., \& Nik Mat, N. K. (2013). Key Drivers in Enhancing Actual Purchase of Local Brand in Saudi Arabia: Intention, Patriotism, Trust, Family and Government Support. Conference on Business Management Research.

Ali, H. (2011). Exchanging Value within Individuals' Networks: Social Support Implications for Health Marketers. Journal of Marketing Management, 27(3-4), 316-335.

Armstrong, A., Abubakar, N. J., \& Sikayena, I. (2017).Investigating into Factors Accounting for Cognitive Dissonance (Post Purchase Regrets). International Journal of Multidisciplinary Research and Development, 4(3), 229-239.

Aronson, E. (1969). The Theory of Cognitive Dissonance: A Current Perspective1. In Advances in experimental social psychology (Vol. 4, pp. 1-34).Academic Press.

Bose, T. K., \& Sarker, S. (2012). Cognitive Dissonance Affecting Consumer Buying Decision Making: A study Based on Khulna Metropolitan Area. Journal of Management Research, 4(3), 191-221.

Brown-Wright, L., Tyler, K. M., Graves, S. L., Thomas, D., Stevens-Watkins, D., \& Mulder, S. (2013). Examining the Associations Among Home-School Dissonance, a Motivation, and Classroom Disruptive Behavior for Urban High School Students. Education and Urban Society, 45(1), 142-162.

Clark, P. W., \& Das, N. (2009).Exploring the use of E-CRM Elements and Effective Website Design as Tools for Reducing Consumer Post-Purchase Cognitive Dissonance. Journal of Technology Research, 1, 1-8.

Cobb, S. (1976). Social Support as a Moderator of Life Stress. Psychosomatic Medicine, 38(5), 300-314.

Cohen, J. B., \& Goldberg, M. E. (1970).The Dissonance Model in Post-decision Product Evaluation. Journal of Marketing Research, 7(3), 315-321.

Cooper, J. (2007). Cognitive Dissonance: 50 Years of a Classic Theory. Sage.

Crano, W. D. (2000).Milestones in the Psychological Analysis of Social Influence. Group Dynamics: Theory, Research, and Practice, 4(1), 68-80.

Dittmar, H., \& Drury, J. (2000).Self-image-is it in the Bag? A Qualitative Comparison Between "Ordinary" and "Excessive" Consumers. Journal of Economic Psychology, 21(2), 109-142.

Engel, J. F., Blackwell, R. D., \& Kollat, D. T. (1978).Consumer Behavior. (3rd ed.). New York: Holt, Rinehart and Winston.

Festinger, L. (1957). A Theory of Cognitive Dissonance: Stanford University Press.

Gan, C. C., \& Ding, H. T. (2014). Pre-purchase Behaviour: Is There a Cognitive Dissonance? Australian Journal of Basic \& Applied Sciences, 8(5), 35-40.

Graff, J., Sophonthummapharn, K., \& Parida, V. (2012).Post-purchase Cognitive Dissonance-Evidence from the Mobile Phone Market. International Journal of Technology Marketing, 7(1), 32-46.

Hall, A., \& Wellman, B. (1985).Social Networks and Social Support. In S. E. Cohen \& S. L. Syme (Eds.), Social Support and Health (pp.23-41).Academic Press.

Harmon-Jones, C., Schmeichel, B. J., Inzlicht, M., \& Harmon-Jones, E. (2011). Trait Approach Motivation Relates to Dissonance Reduction. Social Psychological and Personality Science, 2(1), 21-28.

Harmon-Jones, E., \& Harmon-Jones, C. (2002).Testing the Action-based Model of Cognitive Dissonance: The effect of Action Orientation on Postdecisional Attitudes. Personality and Social Psychology Bulletin, 28(6), 711-723.

Harmon-Jones, E., \& Harmon-Jones, C. (2007). Cognitive Dissonance Theory After 50 Years of Development. Zeitschriftfür Sozialpsychologie, 38(1), 7-16.

Hasan, U., \&Nasreen, R. (2012).Cognitive Dissonance and its Impact on Consumer Buying behaviour. IOSR J Bus Manage, 1(4), 7-12.

Hettiarachchi, H. A. H., Wickramasinghe, C. N., \& Ranathunga, S. (2017). Social Commerce and Consumer Decision Making: A Conceptual Model from Social Support Perspective. Sixth International Conference on Advances in Economics, Social Science and Human Behaviour Study. 
Holloway, R. J. (1967). An Experiment on Consumer Dissonance. The Journal of Marketing,31(1), 39-43.

Horowitz, L. M., Krasnoperova, E. N., Tatar, D. G., Hansen, M. B., Person, E. A., Galvin, K. L., \& Nelson, K. L. (2001). The Way to Console May Depend on the Goal: Experimental Studies of Social Support. Journal of Experimental Social Psychology, 37(1), 49-61.

Hoshino-Browne, E., Zanna, A. S., Spencer, S. J., Zanna, M. P., Kitayama, S., \& Lackenbauer, S. (2005). On the Cultural Guises of Cognitive Dissonance: The Case of Easterners and Westerners. Journal of personality and Social Psychology, 89(3), 294-310.

Hunt, S. D. (1970). Post-Transaction Communications and Dissonance Reduction. The Journal of Marketing,34(3), 46-51.

Jamwal, M., \& Pandey, A. C. Understanding the Impact of Demographics on Post-purchase Cognitive Dissonance. Research Journal of Management Sciences, 5(4), 1-6.

Kamis, A., \& Frank, J. (2012).The Impact of Social Shopping and Customization Support on Students' Intentions to Purchase Online Travel. Journal of Travel and Tourism Research, 12(2), 1-18.

Kelman, H. C. (1958). Compliance, Identification, and internalization three Processes of Attitude change. Journal of conflict resolution, 2(1), 51-60.

Korgaonkar, P. K., \& Moschis, G. P. (1982).An Experimental Study of Cognitive Dissonance, Product Involvement, Expectations, Performance and Consumer Judgment of Product Performance. Journal of Advertising, 11(3), 32-44.

Kotler, P., \& Armstrong, G. (2010). Principles of Marketing. Pearson Education.

Li, Y. M., \& Lai, C. Y. (2014). A social Appraisal Mechanism for Online Purchase Decision Support in the Micro-blogosphere. Decision Support Systems, 59, 190-205.

Mao, W., \& Oppewal, H. (2010). Did I Choose the Right University? How Post-purchase Information Affects Cognitive Dissonance, Satisfaction and Perceived Service Quality. Australasian Marketing Journal $(A M J), 18(1), 28-35$.

McKimmie, B. M., Terry, D. J., Hogg, M. A., Manstead, A. S., Spears, R., \& Doosje, B. (2003). I'm a hypocrite, but so is everyone else: Group Support and the Reduction of Cognitive Dissonance. Group Dynamics: Theory, research, and practice, 7(3), 214-224.

Milliman, R. E., \& Decker, P. J. (1990).The use of Post-purchase Communication to Reduce Dissonance and Improve Direct Marketing Effectiveness. The Journal of Business Communication, 27(2), 159-170.

Montgomery, C., \& Barnes, J. H. (1993). POSTDIS: A Short Rating Scale for Measuring Post- purchase Dissonance. Journal of Consumer Satisfaction, Dissatisfaction and Complaining Behavior, 6(1), 204-216.

Nail, P. R., \& Boniecki, K. A. (2011). Inconsistency in Cognition: Cognitive Dissonance. In D. Chadee (Ed.), Theories in Social Psychology (pp. 44-71).Wiley-Blackwell.

Oliver, R. L. (1997). Emotional Expression in the Satisfaction Response. In R. L. Oliver (Ed.), Satisfaction: A Behavioral Perspective on the Consumer (pp. 291-325). Irwin-McGraw-Hill.

O'Neill, M., \& Palmer, A. (2004).Cognitive Dissonance and the Stability of Service Quality Perceptions. Journal of Services Marketing, 18(6), 433-449.

O'Reilly, P. (1988). Methodological Issues in Social Support and Social Network Research. Social Science \& Medicine, 26(8), 863-873.

Oshikawa, S. (1972). The Measurement of Cognitive Dissonance: Some Experimental Findings. The Journal of Marketing, 36(1), 64-67.

Reiger, R. C. (2000). Examining the" Cognitive Dissonance" of Students at Pleasantville High School by Grade and by Gender. Education, 121(1), 38-43.

Rodrigues, L., Blondé, J., \& Girandola, F. (2018).Social Influence and Intercultural Differences. In C. Faucher (Ed.), Advances in Culturally-Aware Intelligent Systems and in Cross-Cultural Psychological Studies (pp. 91-413). Springer, Cham

Schiffman, L. G. \& Kanuk, L. (2009).Consumer Behavior, 6th Ed. Boston Prentice Hall.

Sharma, M. K. (2014). The Impact on Consumer Buying Behaviour: Cognitive Dissonance. Global Journal of Finance and Management, 6(9), 833-840.

Sheth, J.N., (1969). The Theory of Buyer Behavior. New York: Wiley.

Shultz, T. R., \& Lepper, M. R. (1996).Cognitive Dissonance Reduction as Constraint Satisfaction. Psychological Review, 103(2), 219-240. 
Soliman, A. M. (1993). Choice of Helpers, Types of Problems and Sex of Helpers of College Students. International Journal for the Advancement of Counselling, 16(2), 67-79.

Soutar, G. N., \& Sweeney, J. C. (2003). Are There Cognitive Dissonance Segments?. Australian Journal of Management, 28(3), 227-249.

Sweeney, J. C., Hausknecht, D., \& Soutar, G. N. (2000). Cognitive Dissonance After Purchase: A multidimensional Scale. Psychology \& Marketing, 17(5), 369-385.

Tanford, S., \& Montgomery, R. (2015).The Effects of Social Influence and Cognitive Dissonance on Travel Purchase Decisions. Journal of Travel Research, 54(5), 596-610.

Taylor, S., \& Todd, P. A. (1995).Understanding Information Technology Usage: A Test of Competing Models. Information Systems Research, 6(2), 144-176.

Telci, E. E., Maden, C., \& Kantur, D. (2011). The Theory of Cognitive Dissonance: A Marketing and Management Perspective. Procedia-Social and Behavioral Sciences, 24, 378-386.

Thoits, P. A. (1986). Social Support as Coping Assistance. Journal of Consulting and Clinical Psychology, 54(4), 416-423.

Thompson, S. C., Pitts, J. S., \& Schwankovsky, L. (1993). Preferences for Involvement in Medical Decisionmaking: Situational and Demographic Influences. Patient Education and Counseling, 22(3), 133-140.

Van Overwalle, F., \& Jordens, K. (2002).An Adaptive Connectionist Model of Cognitive Dissonance. Personality and Social Psychology Review, 6(3), 204-231.

Zimet, G. D., Dahlem, N. W., Zimet, S. G., \& Farley, G. K. (1988). The Multidimensional Scale of Perceived Social Support. Journal of Personality Assessment, 52(1), 30-41. 